\title{
The impact of a musculoskeletal masters course: Developing clinical expertise
}

\author{
Nicola J. Petty, Julie Scholes, Lorraine Ellis
}

Keywords: Clinical expertise Masters course

Musculoskeletal physiotherapy Work-based learning

\section{a b s t r a c t}

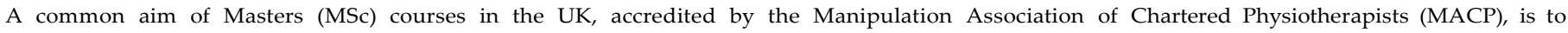

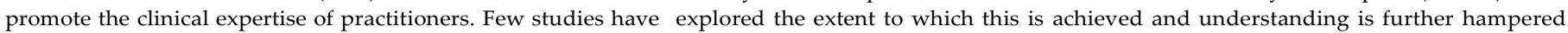

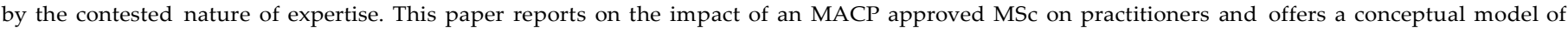
their development towards clinical expertise.

A qualitative theory-seeking case study was used, drawing on the procedures and processes of grounded theory. Twenty-six semi-structured

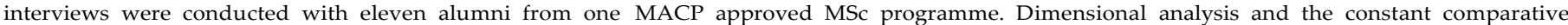
method of data analysis, was used to build the conceptual model.

Prior to enrolment, practitioners uncritically accepted knowledge from others and followed habitual routines with their patients. Their diet of

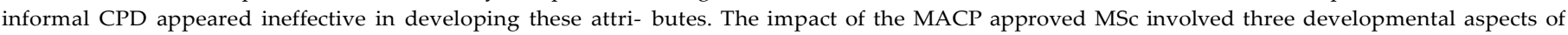

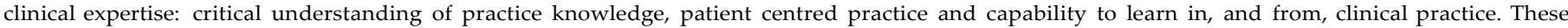

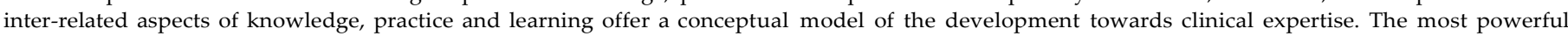

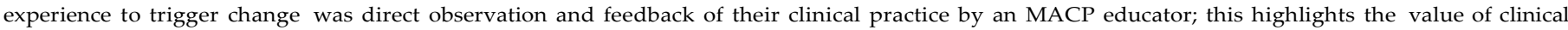

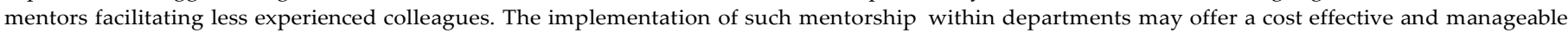
way to support CPD within the workforce.

\section{Introduction}

In 1992, the first clinically orientated masters (MSc) course was set up and accredited by the Manipulation Association of Chartered Physiotherapists (MACP). There are now eleven MACP approved MSc courses in the United Kingdom (UK), all of which satisfy international academic standards for musculoskeletal physiotherapy education (International Federation of Orthopaedic Manipulative Physical Therapists [IFOMPT], 2008) and undergo regular national and international quality monitoring (Rushton and Petty, 2002). A major aim of both the MACP and IFOMPT is to promote excellence in clinical standards of musculoskeletal physiotherapists and this is reflected in the course requirement of $200 \mathrm{~h}$ of neuromusculoskeletal physiotherapy theory, $150 \mathrm{~h}$ of practical skill development and $150 \mathrm{~h}$ of mentored clinical practice (International Federation of Orthopaedic Manipulative Physical Therapists [IFOMPT], 2008).
The importance of the clinical placements to develop clinical expertise has been highlighted by Rushton and Lindsay (2007) and is consistent with the literature related to situated learning (Fish and Coles, 1998; Billett, 2001, 2004; Dall'Alba and Sandberg, 2006) and mentorship (Daloz, 1999; Jensen et al., 1999). New knowledge and skills need to be learnt within the setting to which it is to be applied. Learning facilitated by an experienced mentor giving guidance, challenge and support to a less experienced practitioner can help to consolidate applied theory and expose new opportunities for learning. This helps explain why mentored clinical practice is considered so important to students. MACP approved courses provide a significant step towards advanced clinical practice and specialisation (Carr and Shepherd, 1996; Chartered Society of Physiotherapy, 2002a, 2002b; Robertson et al., 2003) with enhanced career development (Stathopoulos and Harrison, 2003; Conneeley, 2005; Green et al., 2007) that includes advanced practitioner and consultant roles within the UK NHS (Department of Health, 2008). A variety of publications document the expected learning outcomes following Masters level study in the UK (Chartered Society of Physiotherapy, 1998; 

International Federation of Orthopaedic Manipulative Physical Therapists [IFOMPT], 2008, Quality Assurance Agency Qualifications Framework, 2008; The European Qualifications Framework for Lifelong Learning, 2008). While Masters level study is likely to affect the practitioner, the workplace, patients and the profession (Gosling, 1999), the focus of this paper is the impact on the practitioner and their clinical practice.

Only three studies have explored the impact of an MACP approved MSc on practitioners (Stathopoulos and Harrison, 2003; Green et al., 2007; Rushton and Lindsay, 2010); the findings are summarised in Table 1. Stathopoulos and Harrison (2003) carried out a phenomenological study using focus group interviews with five practitioners, three of whom had completed an MACP approved MSc. Practitioners became more confident, more patient centred and developed enhanced clinical reasoning. They gained a greater depth of knowledge and were able to critically synthesise the evidence to inform their practice. They also developed a greater awareness of how to learn. Similar findings were found by Green et al. (2007) who used a postal questionnaire to investigate the career development of 48 practitioners from one MACP approved MSc. Similarly, a North American study using a postal questionnaire of 90 alumni from an American Orthopaedic residency programme, approved by the American Academy of Orthopaedic Manual Physical Therapy (member organisation of IFOMPT), also found practitioners gained enhanced clinical reasoning and a better ability to critically evaluate and apply evidence-based practice (Smith et al., 1999).

More recently, a theoretical construct of Masters level clinical practice has been conceptualised by triangulating the findings from a Delphi study (Rushton and Lindsay, 2008) and an exploratory case study (Rushton and Lindsay, 2010) with involvement of university tutors, students and clinical tutors. Masters level clinical practice was described as a combination of three overlapping entities: high level clinical reasoning, advanced use of knowledge and high level of personal characteristics (e.g. criticality, creativity and reflective practice), operating within the context of evidence-based and patient centred practice (Rushton and Lindsay, 2010). While this more comprehensive description of master level clinical practice builds on previous research findings (Stathopoulos and Harrison, 2003; Green et al., 2007) and offers a sound framework to inform curriculum development, it raises further questions. The interrelationship between clinical reasoning, knowledge and personal characteristics, as well as between patient centred practice and evidence-based practice remains unclear. Understanding the dynamic relationship between these characteristics may help

Table 1

Impact of an MACP approved MSc on practitioners.

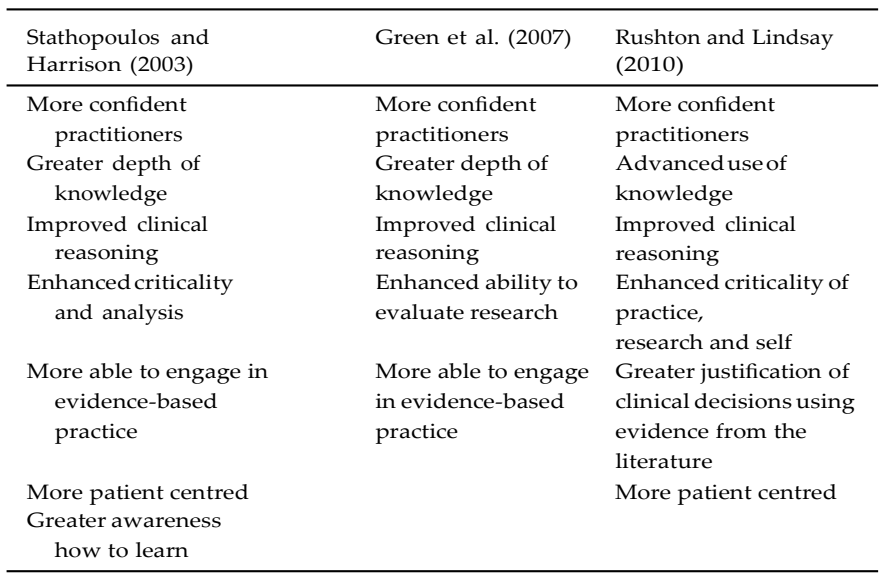

inform curriculum design and delivery for educational programmes that seek to promote clinical expertise. This paper explores the impact of an MACP approved MSc on practitioners and offers a conceptual model of their development towards clinical expertise.

\section{Methodology}

\subsection{Design}

A naturalistic enquiry (Guba and Lincoln, 1981; Erlandson et al., 1993) using a single theory-seeking case study design (Bassey, 1999; Simons, 2009) was used and closely resembled the procedures and processes of grounded theory (Morse et al., 2009). This paper reports on practitioners' perceived learning outcomes following successful completion of an MACP approved MSc. These learning outcomes form part of a broader theory on the learning transition of practitioners reported elsewhere (Petty et al., 2010).

\subsection{Participants}

Thirty five alumni who had successfully completed the MSc Neuromusculoskeletal Physiotherapy from one UK university were identified from the open access pages of the MACP website (http:// macpweb.org). Purposive sampling was used to select alumni from a wide range of experiences and from different cohorts, graduation years, work settings and gender. Biographical data is given in Table 2. Eleven alumni agreed to take part and gave informed consent. Ethical approval was obtained from the research and ethical committee of the local university.

\subsection{Methods}

A total of 26 audio-recorded, telephone or face to face semistructured interviews (amounting to $19 \mathrm{~h}$ ) were conducted between January 2005 and April 2007. All but one participant was interviewed two or three times. The interview agenda for the first, second and third round of interviews is shown in Table 3.

The insider status of the researcher gave credibility to the study and facilitated a comfortable and trusting relationship with the researcher. Participants believed they could be honest as the subsequent power relationship with the researcher was no longer in existence. In the first interview, the last question aimed to diminish potential bias, by exploring it openly with participants'. The researcher (NJP) had been course leader and module leader of MACP specific modules when study participants had undertaken the MSc, and remained in these roles during the study. The MACP specific modules were two university-based modules covering neuromusculoskeletal theory and practical skill development and two clinical placements involving mentored clinical practice.

Table 2

Profile of participants $\left(N \frac{1}{4} 11\right)$

$\begin{array}{ll}\text { Mean age } & 38.2 \text { (range } 31 \mathrm{e} 52) \\ \text { Mean years in clinical practice } & 8.5 \text { (range } 3 \mathrm{e} 24) \\ & \\ & 4 \text { in private practice } \\ & 7 \text { in NHS: } \\ & 1 \text { at band } 7 \text { (Advanced Practitioner) } \\ & 4 \text { at band } 8 \text { A (Extended Scope Practitioner) } \\ & 2 \text { at } 8 \mathrm{~B} \text { (Consultant Practitioner) }\end{array}$

Mean years since completed 2.4 (range 2 monthse 5 years)

MACP approved MSc 
Table 3

First, second and third interview agendas.

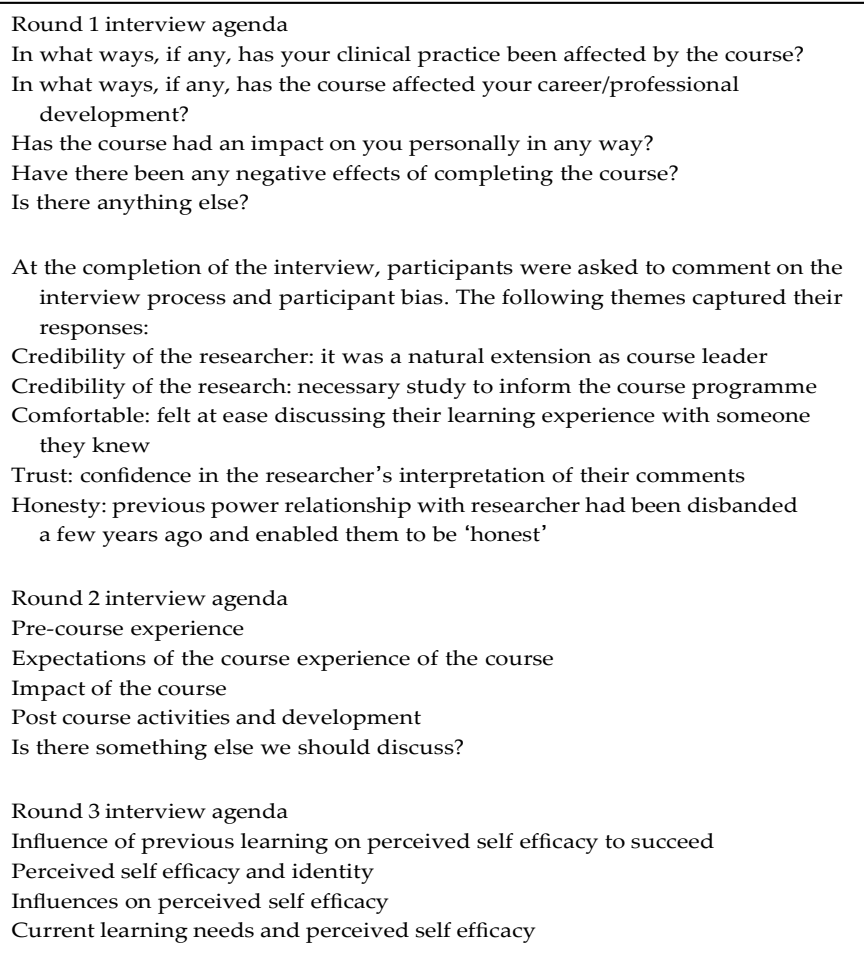

The knowledge gleaned over 10 years was considered data in the form of observational memory and helped inform data analysis.

\subsection{Data analysis}

Dimensional analysis (DA) draws upon the 'core practices' of grounded theory (GT) (Schatzman, 1991: 303), but has its own specific procedures and philosophical history that distinguishes it from GT. DA provides the researcher with interpretive procedures to help order their analysis. These include: reading transcripts, labelling data (properties), recasting these labels with more abstracted terms that clarify meaning (dimensions), and building patterns between these abstracted terms to explain a social process (Kools et al., 1996). This enables the analyst to see the data from a different theoretical perspective, re-reading the original transcript to label data to challenge, confirm or create new explanation. This cyclical process is then supported by comparison across other cases to identify difference and commonality that can shift the perspective or theoretical view of the data. Thus dimensions are built inductively but their veracity are checked by deductive measures to confirm or refute their significance. The data are then challenged to see if this perspective provides a central organising phenomenon around which other dimensions orbit. This is written as an explanatory matrix that tells a story of the context, conditions, actions/processes and the consequences of the social interaction under review (Schatzman, 1991: 308). Each phase is driven by analytical questions that help to interrogate the data and theoretical memos that provide an audit trail of the decisions made during the analytical procedure.

Analysis of the first round of interviews identified a number of learning outcomes and students' experiences from the course, but failed to identify the learning process involved. Role and learning transition theory (Allen and van de Vliert, 1984; Scholes, 2006) and social learning theory (Bandura, 1977, 1997) provided a theoretical framework to examine the learning process involved to achieve these outcomes. This provided greater theoretical sensitivity to guide round two and three interview agendas and subsequent analysis.

\subsection{Trustworthiness}

The researcher and participants had a shared knowledge of the MSc course programme and this could be construed as insider research (Robson, 2002). However the focus of this study was an exploration of the participant's experience of their learning journey, to which the researcher was unaware and was thus an outsider (Mercer, 2007). Nevertheless, the close involvement of the researcher required strategies to minimise bias that would otherwise threaten the trustworthiness of the study (Mercer, 2007). The researcher reduced bias by taking a reflexive and critically reflective stance throughout data collection and analysis. Transcribing each interview, for example, enabled critical reflection on the interview process and the researcher's influence on the data with subsequent interviews enabling understanding to be checked. The three years of data collection and analysis allowed development of a strong researcher identity and researchereparticipant relationship with disentanglement from the roles of course and module leader. The initial interview provided an opportunity to debrief and explore the impact of the course on their practice. In subsequent interviews, most of which were by telephone, participants' revealed more personal and difficult experiences of the course. The iterative process of data collection and analysis enabled frequent verification checks to be made with participants. Formal and informal critical evaluation of the findings by current students and colleagues was also obtained. Rigorous testing out of ideas throughout data analysis was considered essential to the trustworthiness of the study.

\section{Findings}

Practitioners (referred to as P1, P2 etc) described the impact of the MSc by comparing it to their practice prior to enrolment; for this reason the findings are presented in a similar way. The term 'practice knowledge' is used to include all types of knowledge (propositional, practical, tacit etc) used in clinical practice including cognition, metacognition, reflection and clinical reasoning (Eraut, 1994; Higgs et al., 2004).

\subsection{Prior to enrolment on the MSc}

Participants tended to uncritically accept knowledge from research articles, 'I read a paper and if it's good, it might make me think I must do that in my practice'(P1) and from those teaching weekend courses where they were 'given recipes and approaches' (P3). Participants understanding of practice knowledge was limited and this adversely affected their clinical practice, 'I wasn't quite sure when or why I should treat.I had a whole range of techniques I could use but I wasn't sure when to apply them' (P3); 'I sort of threw a technique at the problem'(P11).

Clinical practice was characterised with habitual routines with patients, 'I was just going through a process because that was the process I'd been taught to do' (P4), using 'recipe treatments and pathology based treatments'(P3). Participants tended to apply techniques to patients with little critical evaluation of effectiveness, 'It might be quite a few treatments down the line before you're really thinking 'am I actually helping the problem?' (P2) Their professional development activities involved in-service training and weekend courses, but this was 'not really helping me pull it all together'(P2); and this triggered a number of participants to enrol onto the MSc. Participants appeared dependent on others for knowledge with little disposition to critically evaluate knowledge. 
They demonstrated an over reliance on propositional knowledge with little use of experiential or tacit knowledge and metacognition and appeared to have a technical rationale view of clinical practice (Fish and Coles, 1998).

\subsection{Successful completion of the MSc}

Participants enhanced their practice in terms of three interrelated aspects: they gained a critical understanding of practice knowledge that facilitated more patient centred practice, which led to a capability to learn in and from practice. These three aspects of clinical expertise are depicted in Fig. 1. While the large arrowhead indicates the overall direction of development, the small arrowheads highlight that patient centred practice enhanced understanding, and learning from practice enhanced patient centred practice. The most powerful learning process of the MSc was on clinical placement with an MACP approved clinical educator; this involved direct observation of their clinical practice with patients with subsequent questioning, discussion and critical feedback. In addition, participants observed the educator with patients who sometimes became 'a really good role model' (P10).

\subsubsection{Critical understanding of practice knowledge}

Participants gained a deeper understanding of practice knowledge, 'I (came) to look at everything I did in a much deeper way' (P1). They understood why they were asking the questions in the subjective examination and why they were performing the tests in the physical examination, 'You know exactly why you've done each test and for what reason'(P2). Participants demonstrated more overt metacognition in their practice, became less dogmatic and more open to alternative ways to practice, "helped me understand there are two or three ways to do something, before I used to think there was only one way to do something'(P10). This suggests participants' thinking moved from dualism towards relativism (Perry, 1970).

Enhanced understanding impacted on their treatment and management of patients. They became more deliberate and creative with a greater ability to justify their decisions, 'I can move logically, but still quite creatively, and can justify what I am actually doing'(P7); 'Once you understand the anatomy, biomechanics, and pathologies, you can then treat anything in any situation'(P1). Practice thus became contingent and was viewed as professional artistry (Fish and Coles, 1998).

Participants gained enhanced criticality towards research, 'able to review new literature in a much better way'(P4), 'I don't just read the journal and think everything's absolutely right, I question everything'(P9) and toward their own clinical practice and that of others, they became 'more confident to challenge myself and other people on diagnosis or progression'(P3). They had become more critically evaluative of research and used research evidence more judiciously so that 'decisions around assessment and treatment are more accurate and informed, based around the evidence'(P10). Participants demonstrated a shift from uncritical acceptance to critical evaluation and application of propositional knowledge.

For most participants their enhanced understanding of their practice enabled them to communicate more effectively with patients, 'You have to have the evidence to know why you are doing that and then you've got to then sell that to the patient.. the more you feel you're confident about something, then the better you're going to impart that knowledge'(P4). They thus gained enhanced self efficacy in their practice knowledge (Bandura, 1997).

Deep conceptual understanding with integration of all types of knowledge and an ability to critically evaluate knowledge is considered characteristic of expertise (Sandberg, 2000; Benner, 2004; Higgs and Jones, 2008) and enabled them to become more patient centred.

\subsection{Patient centred practice}

Patient centred practice is used here to refer to the conscious, deliberate, creative and individualised clinical care of patients (Eraut, 1994; Martin et al., 1999; Higgs and Titchen, 2000). Participants' practice became more deliberate and individualised,'I used to think all shoulders are the same and all hips are the same. I then saw each patient more as an individual'(P1).

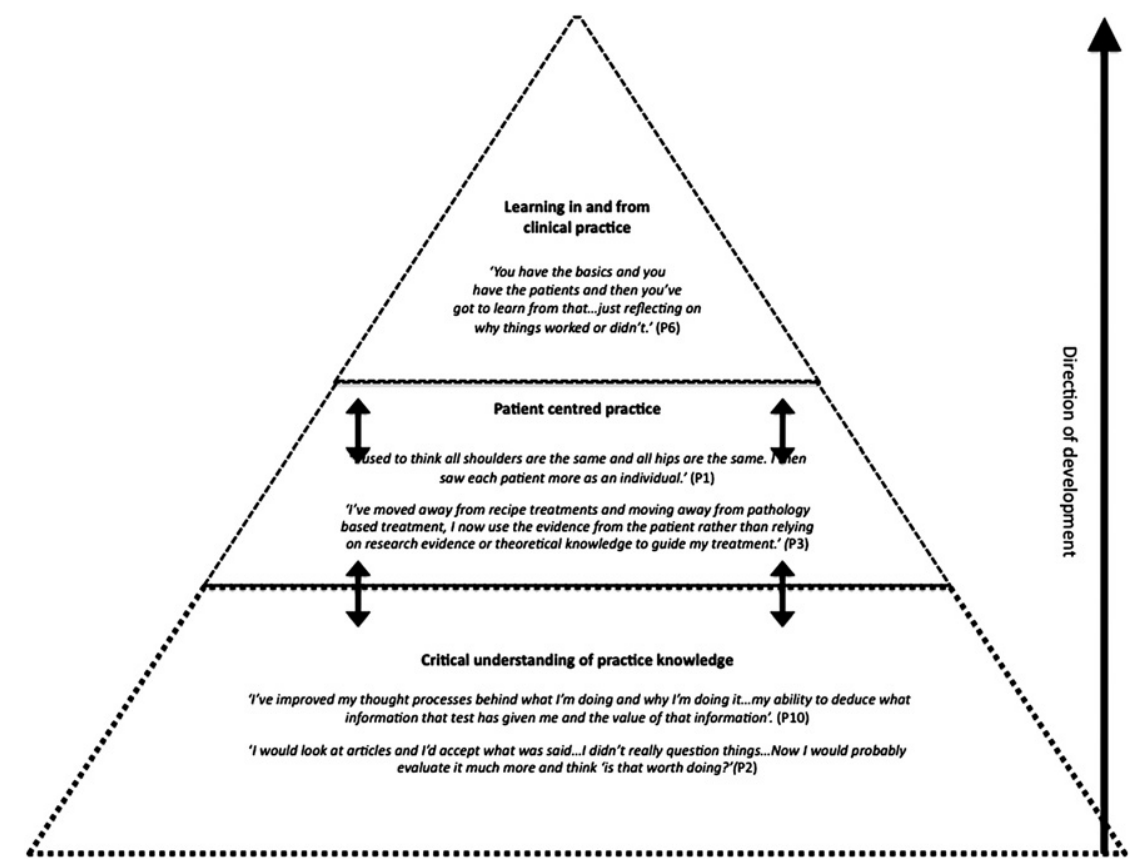

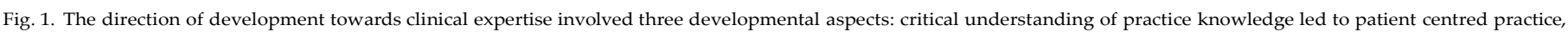

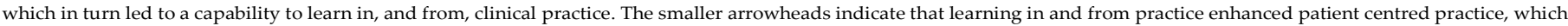
in turn enhanced critical understanding of practice knowledge. 
While a more creative, deliberate and individualised approach would enhance collaboration with the patient, the degree to which this was achieved remained unclear. There were limitations in their assessment of patients, 'fear, attitudes and beliefs about the pain are a huge component and I don't know that the course helped me much with that' (P2); 'It (The course) didn't address the yellow flags and centrally sensitised people and affective disordered people. it was all about mechanical pain'(P10). The main focus of the course was developing practitioner's diagnostic reasoning for patients with physical impairments and this was borne out in the data.

Assessment findings were now used to guide treatment choice and 'gave me the freedom to create treatment techniques to suit me and the patient'(P6). Greater depth of understanding and knowledge of the principles underpinning practice enabled them to better manage patients with more complex and recurrent presentations. While understanding enabled the practitioner to adapt and be creative in their practice to meet the needs of the individual, criticality led to continual assessment, analysis and evaluation of patient management to ensure practice was effective for the patient. Offering this more flexible approach to meet the needs of individual patients enhanced their ability to learn in, and from, practice.

\subsection{Learning in and from practice}

Participants questioned and evaluated their practice, no longer assuming they were effective and this then enabled them to learn in, and from, their practice, 'Each patient is like an individual piece of research, each one adds to your knowledge and experience' (P5); '(the course) teaches you how to learn. You have the basics and you have the patients and then you've got to learn from that.why did that work, why did this not work?'(P6) Over time, this process enhanced their prognostic judgement, 'I know who I can and can't help'(P7).

The majority of participants commented on a greater ability to learn on their own and this reduced their attendance at weekend courses. Almost all talked about their continued thirst to learn after the MSc and drive to improve their practice, 'I can always do better and improve myself as a clinician'(P10). Participants became more autonomous learners 'I do far less weekend courses because I don't think there are any courses out there that can teach me anything more than I can learn on my own'(P1). Their reduced attendance at weekend courses suggests their practice became the learning environment for them. This may indicate that their practice knowledge was fashioned in such a way that it was coherent and consistent with their clinical practice. They were able to not only operate in the messy and unpredictable world of clinical practice, but were able to learn from it. This capability to learn in, and from, practice is considered essential not only to develop but also to maintain clinical expertise (Eraut, 1994; Fish and Coles, 1998; Daley, 1999; Martin et al., 1999; Benner, 2004).

\section{Discussion of findings}

The attributes of clinical expertise identified in this study are conceptualised within three developmental strands: critical understanding of practice knowledge, patient centred practice and a capability to learn in, and from practice. These inter-related aspects of knowledge, practice and learning offer a new conceptual model to explain the development of autonomous and critically reflective practitioners. While previous studies have demonstrated individual attributes of clinical expertise (Stathopoulos and Harrison, 2003; Green et al., 2007; Rushton and Lindsay, 2010), this study proposes a dynamic process that enabled practitioners to develop expertise.

Prior to enrolment, practitioners uncritically accepted knowledge from others and were dependent on others to learn; this has been reported elsewhere (Richardson, 1999; Smith et al., 1999; Stathopoulos and Harrison, 2003; Conneeley, 2005; Green et al., 2007). They followed routines in their practice, and were not able to adapt to individual patients. Their diet of informal CPD (weekend courses and in-service training) appeared ineffective in changing these attributes.

Pivotal to learning during the MSc was direct observation and feedback of their clinical practice by an MACP educator. Questioning by the educator enabled the practitioner to become aware of their assimilated hidden, taken for granted knowledge (Titchen, 2001). It is proposed that through critical enquiry this knowledge became less personally embedded (Kegan, 2000), more discriminating, integrated, differentiated, open (Mezirow, 1991), dependable and justified (Cranton, 2000) leading to more complex and comprehensive embodied understanding (Dall'Alba, 2004; Dall'Alba and Sandberg, 2006). This learning process enhanced their understanding of, and criticality towards, practice knowledge, which is considered essential for patient centred practice (Fish, 1998; Fish and Coles, 1998; Johns, 1998). While practitioner's developed a more creative, deliberate and individualised patient centred approach, their attention to psychosocial issues appeared limited; this reflected the course curriculum at the time. The emphasis was on diagnostic reasoning and further study post MSc into the complexity of psychosocial issues would be needed. The acknowledged importance of psychosocial factors in the management of patients with musculoskeletal conditions (e.g. Jack et al., 2010) challenges this situation and demands a greater integration within the MSc course.

In addition, practitioners observed the educator with patients, gaining insight into a higher level of practice and hearing the subsequent questions posed by the educator as they reflected on the encounter. The educator modelled a way of learning that triggered in the practitioner 'growth of the inner teacher' (Daloz, 1999, p218). This highlights the value and effective role of a mentor with high levels of clinical expertise facilitating less experienced colleagues. While the CSP advocate workplace learning (Chartered Society of Physiotherapy, 2005a, 2005b), perhaps the value of direct observation has yet to be realised (Petty and Morley, 2009). The implementation of such mentorship with departments using the notion of critical companionship (Titchen, 2001) may not only develop a dynamic learning environment but may also be a cost effective and manageable way to support CPD within the workforce.

It should be remembered the model was developed from the perceived impact on alumni after completion of the course. A further limitation of the study was that it was carried out with alumni from only one MSc course in the UK. The findings have been constructed by the researcher from data co-created with the participants; and as such is caught in time and place. While the findings cannot automatically be generalised, they may be transferrable to other similar situations.

\section{Conclusion}

The findings of this study add to the growing body of evidence of the effectiveness of MACP approved MSc programmes in developing the clinical expertise of practitioners. The attributes of expertise identified in this study are conceptualised within three developmental and inter-related strands: critical understanding of practice knowledge, patient centred practice and a capability to learn in, and from practice. These inter-related aspects of knowledge, practice and learning offer a new conceptual model of the development of practitioners towards clinical expertise. This developmental process towards autonomous and critically reflective practitioners may inform educationalists and practitioners who seek to promote clinical expertise within neuromusculoskeletal physiotherapists. 


\section{Acknowledgements}

The authors wish to thank the participants who took part in this study and Guy Canby, Colette Ridehalgh and Dr Vinette Cross for critically commenting on the manuscript.

\section{References}

Allen VL, van de Vliert E. Role transitions, explorations and explanations. New York Plenum; 1984.

Bandura A. Social learning theory. Englewood Cliffs: Prentice-Hall; 1977.

Bandura A. Self perceived self efficacy, the exercise of control. New York: W H Freeman and Co; 1997.

Bassey M. Case study research in educational settings. Maidenhead: Open University; 1999.

Benner P. Using the Dreyfus model of skill acquisition to describe and interpret skill acquisition and clinical judgement in nursing practice and education. Bulletin of Science, Technology and Society 2004;24(3):188e99.

Billett S. Knowing in practice: re-conceptualising vocational expertise. Learning and Instruction 2001;11:431e52.

Billett S. Workplace participatory practices, conceptualising workplaces as learning environments. The Journal of Workplace Learning 2004;16(6):312e24.

Carr J, Shepherd R. Clinical physiotherapy specialisation in Australia: some current views. Australian Journal of Physiotherapy 1996;42(1):9e14.

Chartered Society of Physiotherapy. Expectations of M level programmes for chartered physiotherapists (CPD 24). London: Chartered Society of Physiotherapy; 1998.

Chartered Society of Physiotherapy. Chartered physiotherapists working as extended scope practitioners (ESP) (Information paper PA29). London: Chartered Society of Physiotherapy; 2002a.

Chartered Society of Physiotherapy. Physiotherapy consultant (NHS): role, attributes and guidance for establishing posts (Information paper PA56). London: Chartered Society of Physiotherapy; 2002b.

Chartered Society of Physiotherapy. Workplace learning, evidencing through reflection and evaluation (Information paper CPD 31). London: Chartered Society of Physiotherapy; 2005a.

Chartered Society of Physiotherapy. A guide to implementing clinical supervision (Information paper CPD 37). London: Chartered Society of Physiotherapy; 2005b.

Conneeley AL. Study at master's level: a qualitative study exploring the experience of students. British Journal of Occupational Therapy 2005;68(3):104e9.

Cranton P. Individual differences and transformative learning. In: Mezirow J, editor. Learning as transformation, critical perspectives on a theory in progress. California: Jossey-Bass; 2000. p. 181e204.

Daley BJ. Novice to expert: an exploration of how professional learn. Adult Education Quarterly 1999;49(4):133e47.

Dall'Alba G. Understanding professional practice: investigations before and after an educational programme. Studies in Higher Education 2004;29:679e92.

Dall'Alba G, Sandberg J. Unveiling professional development: a critical review of stage models. Review of Educational Research 2006;76(3):383e412.

Daloz LA. Mentor, guiding the journey of adult learners. San Francisco: Jossey-Bass; 1999.

Department of Health. Modernising allied health professions (AHP) careers, a competence-based career framework. London: Department of Health; 2008.

Eraut M. Developing professional knowledge and competence. London: RoutledgeFalmer; 1994.

Erlandson DA, Harris EL, Skipper BL, Allen SD. Doing naturalistic inquiry, a guide to methods. Newbury Park: Sage; 1993.

Fish D. Appreciating practice in the caring professions. Oxford: Butterworth Heinemann; 1998.

Fish D, Coles C. Developing professional judgement in health care. Oxford: Butterworth Heinemann; 1998

Gosling S. Physiotherapy and postgraduate study, a follow-up discussion paper. Physiotherapy 1999;85(3):117e21.

Green A, Perry J, Harrison K. The influence of a postgraduate clinical master's qualification in manual therapy on the careers of physiotherapists in the United Kingdom. Manual Therapy 2007;13(2):139e47.

Guba EG, Lincoln YS. Effective evaluation: improving the usefulness of evaluation results through responsive and naturalistic approaches. San Francisco: JosseyBass; 1981.
Higgs J, Jones MA. Clinical decision making and multiple problem spaces. In: Higgs J, Jones MA, Loftus S, Christensen N, editors. Clinical reasoning in the health professions. 3rd ed. Amsterdam: Butterworth Heinemann; 2008. p. 3e17.

Higgs J, Richardson B, Dahlgren MA. Developing practice knowledge for health professionals. Edinburgh: Butterworth Heinemann; 2004.

Higgs J, Titchen A. Knowledge and reasoning. In: Higgs J, Jones M, editors. Clinical reasoning in the health professions. 2nd ed. Oxford: Butterworth Heinemann; 2000. p. $23 e 32$.

International Federation of Orthopaedic Physical Therapists. Vision statement. Retrieved from: http://www.ifomt.org/ifomt; 2008 [16.04.10].

Jack K, McLean SM, Klaber Moffett J, Gardiner E. Barriers to treatment adherence in physiotherapy outpatient clinics: a systematic review. Manual Therapy 2010; 15(3):220e8.

Jensen GM, Gwyer J, Hack LM, Shepard KF. Expertise in physical therapy practice. Boston: Butterworth Heinemann; 1999.

Johns C. Becoming a reflective practitioner. 2nd ed. Oxford: Blackwell; 1998.

Kegan R. What "form" transforms? a constructive-developmental approach to transformative learning. In: Mezirow J, editor. Learning as transformation, critical perspectives on a theory in progress. San Francisco: Jossey-Bass; 2000. p. $35 e 69$.

Kools S, McCarthy M, Durham R, Robrecht L. Dimensional analysis: broadening the conception of grounded theory. Qualitative Health Research 1996;6(3): $312 e 30$.

Martin C, Siosteen A, Shepard KF. The professional development of expert physical therapists in four areas of clinical practice. In: Jensen GM, Gwyer J, Hack LM, Shepard KF, editors. Expertise in physical therapy practice. Boston: Butterworth Heinemann; 1999. p. 231e44.

Mercer J. The challenges of insider research in educational institutions: wielding a double-edged sword and resolving delicate dilemmas. Oxford Review of Education 2007;33(1):1e17.

Mezirow J. Transformative dimensions of adult learning. California: Jossey-Bass; 1991.

Morse JM, Stern PN, Corbin J, Bowers B, Charmaz K, Clarke AE. Developing grounded theory, the second generation. Walnut Creek: Left Coast; 2009.

Perry WG. Forms of intellectual and ethical development in the college years. New York: Holt, Rinehart and Winston; 1970.

Petty NJ, Morley M. Clinical expertise: learning together through observed practice. Editorial Manual Therapy 2009;14(5):461e2.

Petty NJ, Scholes J, Ellis L. Masters level study: learning transitions towards clinical expertise in physiotherapy. Physiotherapy; 2010. doi:10.1016/j.physio.2010.11.002.

Quality Assurance Agency for Higher Education. Framework for higher education qualifications in England, Wales and Northern Ireland. Retrieved from: http:// www.qaa.ac.uk/academicinfrastructure/FHEQ/EWNI/default.asp; 2008.

Richardson B. Professional development, professional knowledge and situated learning in the workplace. Physiotherapy 1999;85(9):467e74.

Robertson VJ, Oldmeadow LB, Cromie JE, Grant MJ. Taking charge of change: a new career structure in physiotherapy. Australian Journal of Physiotherapy 2003;49: $229 \mathrm{e} 31$.

Robson C. Real World Research. 2nd edn. Malden: Blackwell; 2002.

Rushton A, Lindsay G. Developing clinical expertise for healthcare professionals through masters courses. International Journal of Therapy and Rehabilitation 2007;14(4):156e61.

Rushton A, Lindsay G. Defining the construct of masters level clinical practice in healthcare based on the UK experience. Medical Teacher 2008;30:e100e7.

Rushton A, Lindsay G. Defining the construct of masters level clinical practice in manipulative physiotherapy. Manual Therapy 2010;15(1):93e9.

Rushton A, Petty N. The course approval board of the manipulation association of chartered physiotherapists. Manual Therapy 2002;7(4):222e8.

Sandberg J. Understanding human competence at work: an interpretative approach Academy of Management Journal 2000;43(1):9e25.

Schatzman L. Dimensional analysis: notes on an alternative approach to the grounding of theory in qualitative research. In: Maines DR, editor. Social organisation and social process. New York: Aldine De Gruyter; 1991. p. 303e14

Scholes J. Developing expertise in critical care nursing. Oxford: Blackwell; 2006.

Simons H. Case study research in practice. Los Angeles: Sage; 2009.

Smith KL, Tichenor CJ, Schroeder M. Orthopaedic residency training: a survey of the graduates' perspective. Journal of Orthopaedic and Sports Physical Therapy 1999;29(11):635e55.

Stathopoulos I, Harrison K. Study at master's level by practising physiotherapists. Physiotherapy 2003;89(3):158e69.

The european qualifications framework for lifelong learning. Luxembourg: Office for Official Publications of the European Communities; 2008.

Titchen A. Critical companionship: a conceptual framework for developing expertise. In: Higgs J, Titchen A, editors. Practice knowledge and expertise in the health professions. Oxford: Butterworth Heinemann; 2001. p. 80 e90. 